\title{
Commentary: The association between hormone-replacement therapy and non-small cell lung cancer in women
}

\author{
Benjamin D. Kozower, MD, MPH
}

\footnotetext{
From the Division of Cardiothoracic Surgery, Department of Surgery, Washington University in St. Louis, St Louis, Mo.

Disclosures: Author has nothing to disclose with regard to commercial support.

Received for publication Oct 1, 2019; revisions received Oct 1, 2019; accepted for publication Oct 1, 2019; available ahead of print Nov 11, 2019

Address for reprints: Benjamin D. Kozower, MD, MPH, Division of Cardiothoracic Surgery, Washington University in St Louis, 660 S Euclid Ave, Campus Box 8234, St Louis, MO 63110 (E-mail: kozowerb@wustl.edu). J Thorac Cardiovasc Surg 2020;159:1557 $0022-5223 / \$ 36.00$

Copyright (C) 2019 by The American Association for Thoracic Surgery https://doi.org/10.1016/j.jtcvs.2019.10.007
}

Titan and colleagues have performed secondary data analyses from data collected by the multicenter randomized Prostate, Lung, Colorectal and Ovarian Cancer Screening Trial (1993-2001). ${ }^{1}$ This longitudinal screening trial collected detailed clinical data, including non-small cell lung cancer (NSCLC) incidence, postdiagnosis therapies, and detailed hormone use. The primary finding of their analyses is that hormone-replacement therapy (HRT) is associated with a $20 \%$ reduction in developing NSCLC. However, HRT was not associated with improved survival following diagnosis and treatment.

We have known for more than a decade that women have a reduced perioperative risk following surgical resection for NSCLC. ${ }^{2}$ Their risk-adjusted mortality risk is $70 \%$ of that found in male patients in the Society of Thoracic Surgeons Database. The reasons for this dramatic difference are poorly understood but have been consistent over time. ${ }^{3}$ The current study uses an epidemiologic approach to investigate the association between HRT and cancer incidence and makes use of a much longer, longitudinal study with a median follow-up of almost 12 years. The authors note the numerous limitations of such a secondary analysis and the steps that they took to mitigate their impact on their primary findings.

In the end, what are women to do? The Women's Health Initiative published in 2002 concluded that "the overall health risks exceeded benefits from use of combined estrogen plus progestin" and demonstrated that HRT raised the risk of breast cancer and did not show a reduction in heart disease. ${ }^{4}$ The use of HRT has never recovered, and the

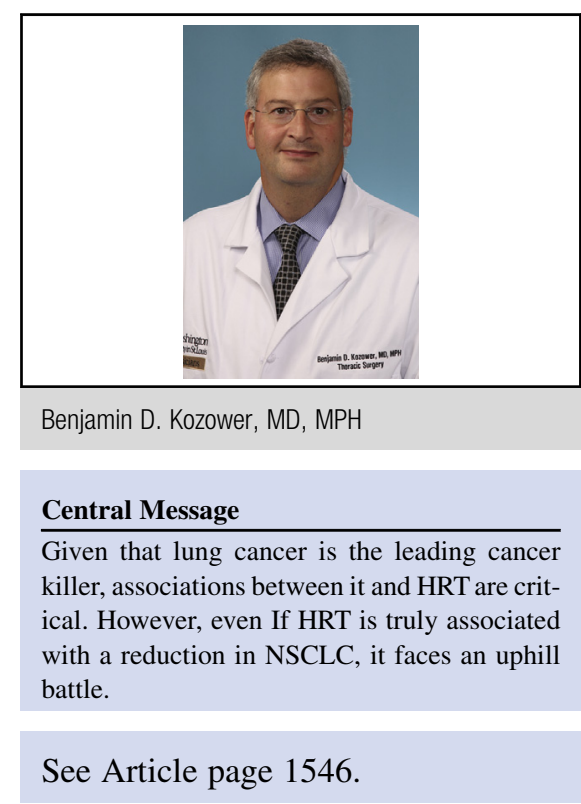

reduction in HRT use may contribute to the rising incidence in lung cancer among women over the past 2 decades. Given that lung cancer is the leading cancer killer in both men and women, studies like these will be critical to inform the debate. However, even If HRT is truly associated with a reduction in NSCLC incidence, it faces an uphill battle.

\section{References}

1. Titan AL, He H, Lui N, Liou D, Berry M, Shrager JB, Backhus L M. The influence of hormone replacement therapy on lung cancer incidence and mortality. J Thorac Cardiovasc Surg. 2020;159:1546-56.e4

2. Kozower BD, Sheng S, O’Brien S, Liptay MJ, Lau CL, Jones DR, et al. STS Database risk models: predictors of mortality and major morbidity for lung cancer resection. Ann Thorac Surg. 2010;90:875-83.

3. Fernandez FG, Kosinski AS, Burfeind W, Park B, DeCamp MM, Seder C, et al Cancer resection risk model: higher quality data and superior outcomes. Ann Thorac Surg. 2016;102:370-7.

4. Writing Group for the Women's Health Initiative Investigators. Risks and benefits of estrogen plus progestin in healthy postmenopausal women. JAMA. 2002;288: 321-33. 